\title{
ACUTE CALCIFIC TENDINITIS OF THE RECTUS FEMORIS AS A SELF-LIMITING CONDITION
}

\author{
Shin-ichi Kanbayashi ${ }^{1)}$, Hideomi Watanabe ${ }^{1)}$, Haruo Uno ${ }^{2)}$, \\ Tetsuo Aramaki ${ }^{1)}$, Kenji Shirakura ${ }^{1)}$, Shigeo Mohara ${ }^{3)}$, \\ Kenji Takagishi ${ }^{1)}$ \\ 1) Department of Orthopedic Surgery, Gunma University Faculty of Medicine, \\ 2) Department of Orthopedic Surgery, Hidaka Hospital, \\ 3) Department of Physical Therapy, School of Health Sciences
}

\begin{abstract}
We report a patient experiencing acute pain in the hip resulting in a limp. Computed tomography and magnetic resonance imaging of the pelvis clearly demonstrated calcification within the iliac tendinous origin of the rectus femoris, although this was obscure in plain radiographs. Laboratory findings revealed a systemic inflammatory reaction. She obtained dramatic relief from pain, which parallel improvement in laboratory data, one day after oral non-steroidal anti-inflammatory drug treatment. Inflammatory responses to hydroxyapatite crystals may play an important role in the pathogenesis of the symptoms induced by calcific tendinitis in the rectus femoris, most of which are self-limiting.
\end{abstract}

Key words: Calcific tendinitis, Rectus femoris, Self-limiting, Inflammatory response (Kitakanto Med.J. 49 (3) : 201 203, 1999)

\section{INTRODUCTION}

Although calcific tendinitis occurs commonly in the shoulder ${ }^{1,2)}$, involvement of the rectus femoris is rare $^{3 \sim 8)}$. Because of the unique location, calcification is obscure in plain radiographs in some cases ${ }^{5}$. We here report a case of calcific tendinitis at this site, which could readily be demonstrated by computed tomography (CT). The patient was treated without the necessity for any local therapy, and was completely cured. Interestingly, the symptoms were parallel with the laboratory findings suggesting inflammation, but not with the radiological progression, as observed for other cases of calcific tendinitis ${ }^{14}$.

\section{CASE REPORT}

A 34-year woman presented a 3-day history of increasing left anterior thigh pain, which caused limping. Physical examination revealed severe tenderness localized over the anterior thigh. The range of motion of her left hip was restricted, and she was only able to flex her hip at 70 degrees, and abduct at 45 degrees. An active straight leg raising test could not be performed due to increasing pain. Remarkable laboratory findings were an elevated white blood cell (WBC) count $\left(10.2 \times 10^{3} / \mathrm{ul}\right.$; normal $\left.<9\right)$, and an elevated CRP $(1.6 \mathrm{mg} / \mathrm{dl}$; normal $<0.6)$. The erythrocyte sedimentation rate (ESR) and serum uric acid were within normal limits. Although no alterations were im-

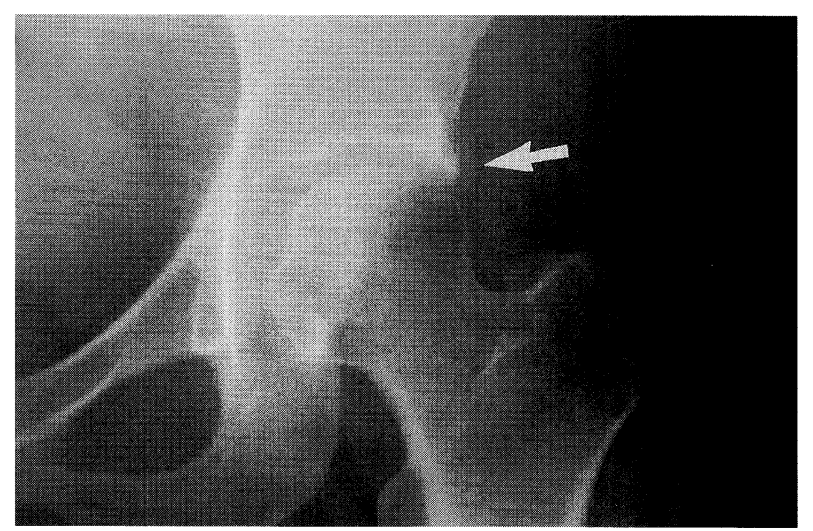

Fig. 1 Plain radiographs showing a faint amorphous calcification close to the superior lip of the acetabulum in the AP view. 


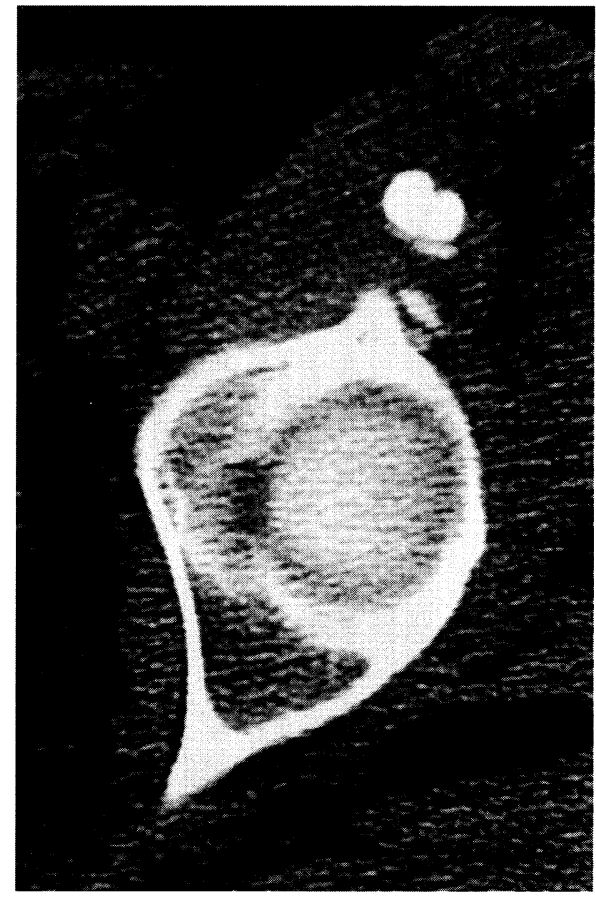

Fig. 2 CT scans demonstrating amorphous soft tissue calcifications in the rectus femoris tendon.

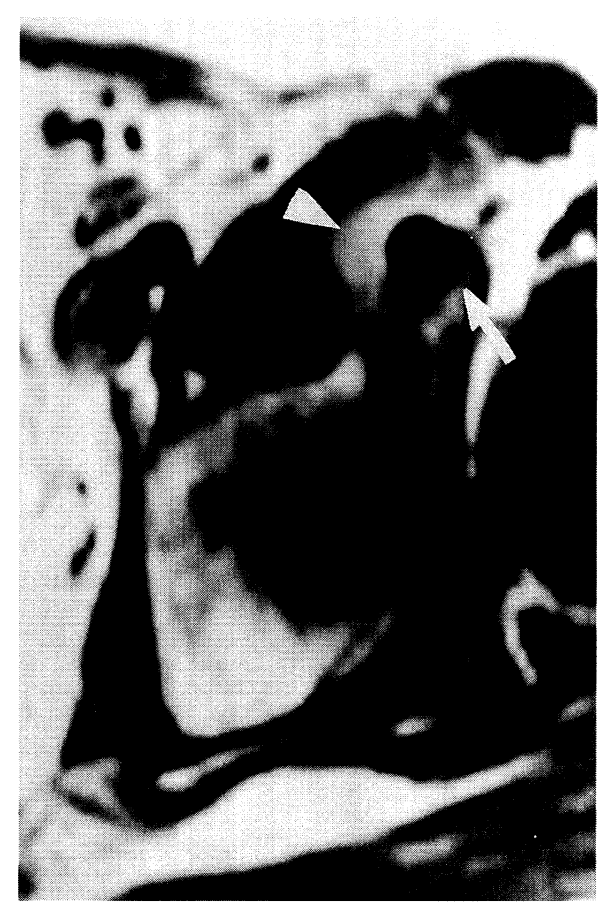

Fig. 3 MRI revealing a low-signal area in the rectus femoris in both T1- and T2-weighted images, corresponding to the calcification (arrow), and an increased signal present in a diffuse area of the surrounding muscle, presumably representing edema (arrowhead).

mediatedly detectable in plain radiographs, careful observation revealed a faint amorphous calcification close to the superior lip of the acetabulum in the AP view (Fig. 1). In contrast, CT scans clearly demonstrated amorphous soft tissue calcifications in the rectus femoris tendon (Fig. 2). On magnetic resonance imaging (MRI), both T1- and T2-weighted images showed a low-signal area in the rectus femoris, corresponding to the calcification, and an increased signal present in a diffuse area of the surrounding muscle, presumably representing edema (Fig. 3).

The patient was given loxoprofen sodium, a nonsteroidal anti-inflammatory drug (NSAID), and symptoms resolved gradually on the next day, and disappeared 3 days later. At that time, the WBC was within the normal range $\left(5.6 \times 10^{3} / \mathrm{ul}\right)$, while $\mathrm{CRP}$ remained mildly elevated $(0.8 \mathrm{mg} / \mathrm{dl})$. On the other hand, the ESR was elevated ( $32 \mathrm{~mm} /$ hour). There was few changes in the radiographic findings. CT scans taken six weeks later revealed disappearance of the calcification . CRP $(0.2 \mathrm{mg} / \mathrm{dl})$ and ESR $(11 / \mathrm{hr})$ were improved into normal range. After a follow-up of one and half years, she did not have a recurrence of symptoms, and no abnormal findings were recognized in radiograph.

\section{DISCUSSION}

Calcific tendinitis results from the deposition of calcium hydroxyapatite crystals in periarticular sites. Although calcific tendinitis occurs commonly in the shoulder $^{1,2)}$, involvement around hip joint is uncommon. Goldenberg and Leventhal reviewed the radiographs of 550 hips in patients between the ages of fifteen and sixty-nine, and found calcified deposits near the greater trochanter in thirty $(5.4 \%)^{9)}$. Among those with calcific tendinitis around hip, involvement of the rectus femoris has been reported to be extremely rare. Presumably, as observed in our case, calcification may not be readily identified on plain radiography because of the location ${ }^{5)}$. However, several authors have reported patients suffering acute onset of pain in the front of the hip and clear periarticular calcification $^{10 \sim 12)}$, with description of bursitis calcarea in iliopectineal bursa ${ }^{11,12)}$. Since the location of the bursa is close to the rectus femoris tendon, the accurate localization of calcification should not be diagnosed only by plain radiography. Differential diagnosis of calcification in the region of rectus femoris also must take into account os acetabuli, avulsion fractures, sesamoid bones, myositis ossificans and malignancies such as juxtacortical chondroma, chondrosarcoma and synovial sarcoma ${ }^{4}$. In the present case, the localization of calcification in the rectus femoris could be elucidated clearly by CT scans. Furthermore, CT and MRI indicated no mass effect in the surrounding soft tissue. These two in combination, may be requisite for pronouncing a correct diagnosis of calcific tendinitis in this location. Sarkar et al. reported that CT facili- 
tates accurate injection as well as allowing accurate localization of the lesion ${ }^{7}$.

The case presented here displayed increases in the laboratory parameters, WBC count and CRP level, indicating of an inflammatory response. To the best of our knowledge, there have been no cases showing laboratory abnormalities related to calcific tendinitis in the rectus femoris tendon reported previously ${ }^{6,7)}$. Laboratory abnormalities related to calcific tendinitis in unusual sites have been described for proximal thigh $^{13,14)}$ and retropharyngeal tendinitis ${ }^{15)}$. The elevated WBC count and CRP improved within one week when clinical resolution was obtained in the present case. The elevation of ESR was delayed compared with those of WBC count and CRP. Slow decline of the ESR compared to CRP has been demonstrated in the acute phase response in calcific tendinitis in the proximal posterior thigh ${ }^{14)}$ as well as a representative crystal-induced disease. Inflammatory responses to hydroxyapatite crystals may play an important role in the pathogenesis of calcific tendinitis in this location as well.

Treatment modalities for calcific tendinitis documented in the literature include irradiation ${ }^{5)}$, resection $^{8)}$, local injection of corticosteroid ${ }^{7)}$, and oral NSAIDs $^{3,6}$. The patient presented here could be successfully treated without any local therapy. In spite of severe complaints and symptoms, rapid relief was observed within one day with oral NSAID, supporting the notion that calcific tendinitis in the rectus femoris is a self-limiting condition. Some authors have recommended percutaneous steroid injection under CTcontrol $^{7}$. If the proper diagnosis of calcific tendinitis is considered by $\mathrm{CT}$ analysis, then overly aggressive surgical management may be avoided. Careful observation of laboratory as well as radiological examinations is to be recommended.

\section{REFERENCES}

1) Thornhill TS. Shoulder pain. In : Kelley WN, Harris ED, Ruddy $\mathrm{S}$ et al (eds). Textbook of Rheumatology, Fourth ed. Philadelphia: WB SAUNDERS COMPANY, 1993: 428-429.

2) Uhthoff HK, Sarkar K, Maynard JA. Calcifying
Tendinitis. Clin Orthop 1976; $118:$ 164-168.

3) Archer BD, Friedman L, Stilgenbauer $S$ et al. Symptomatic calcific tendinitis at unusual sites. Can Assoc Radiol J 1992 ; 43 : 203-207.

4) Holt PD, Keats TE. Calcific tendinitis : a review of the usual and unusual. Skeletal Radiol 1993; 22: 1-9.

5) King JW, Vanderpool DW. Calcific tendonitis of the rectus femoris. Am J Orthop 1967; 9: 110111.

6) Pope TL, Keats TE. Case report 733 : Calcific tendinitis of the origin of the medial and lateral heads of the rectus femoris muscle and the anterior iliac spin. Skeletal Radiol 1992; $21: 271-272$.

7) Sarkar JS, Haddad FS, Crean SV et al. Acute calcific tendinitis of the rectus femoris. J Bone Joint Surg [Br] $1996 ; 78-\mathrm{B}: 814-816$.

8) Ogai H, Fukasawa I, Kurioka $\mathrm{H}$ et al. A case of calcific tendinitis of rectus femoris. J ChugokuShikoku Orthop Assoc 1995; 7: 149. (in Japanese)

9) Goldenberg R R, Leventhal GS. Supratrochnteric calcification. J Bone Joint Surg 1936; 18 : 205.

10) Suematsu N, Sugawara S, Katayama K . Twenty cases of painful calcific periarthritis except shoulder joint. Cent Jpn J Orthop Traumat 1994 ; 37 : 1163-1169. (in Japanese)

11) Sugiura $S$, Umezawa $K$, Saito $Y$ et al. Periarthritis calcarea of the hip joint. Seikeigeka 1986; 37: 1329-1335. (in Japanese)

12) Yamaji K. Acute periarthritis calcarea of hip joint (13 cases report) Cent. Jpn J Orthop Traumat 1986; 29: 540-542. (in Japanese)

13) Hodge JC, Schneider R, Freiberger RH et al. Calcific tendinitis in the proximal thigh. Arthritis Rheum 1993; 36 : 1476-1482.

14) Watanabe $H$, Sano K, Shinozaki $T$ et al. Calcific tendinitis in the posterior proximal thigh as a self-limited condition. J Rheumatol 1998; 25: 970-974.

15) Ring D, Vaccaro AR, Scuderi G et al. Acute calcific retropharyngeal tendinitis. J Bone Joint Surg 1994; 76-A : 1636-1642. 